\title{
WHO Surgical Safety Checklist
}

\author{
Anitha Rego* \\ Trauma \& Orthopedic Theatres, Torbay Hospital, UK \\ *Corresponding author: Anitha Rego, Trauma \& Orthopedic Theatres, Torbay \& South Devon NHS Trust, UK
}

\begin{tabular}{|c|c|}
\hline ARTICLE INFO & ABSTRACT \\
\hline Received: 眥 July 22, 2019 & Citation: Anitha Rego. WHO Surgical Safety Checklist. Biomed J Sci \& Tech Res 20(1)- \\
\hline Published: 幽 July 30, 2019 & 2019. BJSTR. MS.ID.003407. \\
\hline
\end{tabular}

\section{Opinion}

It has been 10 years since the implementation of the World Health Organization (WHO) Surgical Safety Checklist [1]. Adverse events in the operating theatre are a global issue and half of them are often avoidable [2]. As healthcare professionals, the familiar 'first do no harm' principle applies to all regardless of the designation or registration status of the individual practitioner. The impact of adverse events on the individual patient and family as well as the healthcare professional could be devastating. The WHO checklist was developed with an aim to improve the patient safety outcomes in the operating theatre. The checklist consists of a series of checks to be performed during the three phases- 'Signin' before Anaesthesia, 'Time-out' before the surgical incision and 'Sign-out' after the procedure. Each phase is designed to identify and rectify any significant issues before any harm is done i.e. lack of equipment, wrong site surgery and create a shared mental model for effective and safe patient care.

The WHO checklist was pilot tested in a global cohort of 3995 patients in eight countries and showed a reduction of mortality from $1.5 \%$ to $0.8 \%$ and post- surgical complications from $11 \%$ to $7 \%$ with the introduction of the checklist [3]. Still, three years on, Levy et al. [4], in their study, showed that although they had high compliance rates, the checklist could be used as a tick box exercise, thereby questioning the true fidelity of the implementation of the checklist. Any change is challenging particularly in a multidisciplinary setting and especially where changes have been enforced on the frontline professionals without allowing for embedding or change management. Comments such as 'I don't need anyone to tell me how to work safely' were commonly heard during the initial implementation phase in my workplace. Over the last decade, this perception has altered, and the checklist has successfully improved teamwork and communication and has provided added value to the theatre team [5].
Also, the clinical effectiveness of the checklist has been debated over time. Yet, a recent study in Scotland by Ramsay et al. [6] attributes the significant reduction of $36.6 \%$ in their mortality rate from 2000 to 2014 to the effective implementation of the checklist. Significantly, improvement in the safety culture of the healthcare system is paramount to ensure integration of the checklist in the perioperative environment. Likewise, the Global Patient Safety Collaborative [7] has identified leadership, education and training and research as pivotal to enhancing patient safety. And this should start with education in the undergraduate curriculum [8] where the concept of teamwork, effective communication and managing clinical risk should be introduced and linked to patient safety.

Fast forward another decade, and hopefully the education in human factors and the importance of creating a safety culture within the healthcare systems will reap its own benefits. The WHO checklist will be an embedded routine and not an added extra to the next generation of healthcare professionals. Perhaps, it is also important, at this stage, to recognize and not underestimate the high standard of excellent care that the majority of our patients benefit from especially in the face of current adversities such as constant cutbacks, lack of funding, staffing and resources within the healthcare system.

\section{References}

1. (2009) WHO: Implementation Manual WHO Surgical Safety Checklist 2009. Safe Surgery Saves Lives.

2. Vickers R (2011) Five steps to safer surgery. Ann R Coll Surg Engl 93(7): 501-503.

3. Haynes AB, Weiser TG, Berry WR, Lipsitz SR, Breizat AH, et al. (2009) A surgical safety checklist to reduce morbidity and mortality in a global population. N Engl J Med 360: 491-499.

4. Levy SM, Senter CE, Hawkins RB, Zhao JY, Doody K, et al. (2012) Implementing a surgical checklist: more than checking a box. Surgery 152(3): 331-336 
5. Weiser TG, Haynes AB (2018) Ten years of the Surgical Safety Checklist Br J Surg 105(8): 927-929.

6. Ramsay G, Haynes AB, Lipsitz SR, Solsky I, Leitch J, et al. (2019) Reducing surgical mortality in Scotland by use of the WHO Surgical Safety Checklist. Br J Surg 106(8): 1005-1011.

ISSN: 2574-1241

DOI: 10.26717/BJSTR.2019.20.003407

Anitha Rego. Biomed J Sci \& Tech Res

(C) (P) This work is licensed under Creative

Submission Link: https://biomedres.us/submit-manuscript.php
7. (2018) WHO: Global Patient Safety Collaborative Briefing note.

8. (2011) WHO: Patient Safety Curriculum Guide. Multi-professional Edition.

$\begin{array}{ll}\text { BIOMEDICAL } & \text { Assets of Publishing with us } \\ \text { RESEARCHES } & \text { - Global archiving of articles } \\ & \text { - Immediate, unrestricted online access } \\ & \text { - Rigorous Peer Review Process } \\ \end{array}$

